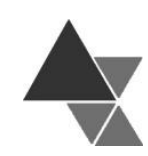

\title{
A experiência brasileira em segurança alimentar e o trabalho do Centro de Excelência contra a Fome do Programa Mundial de Alimentos ${ }^{1}$
}

\author{
Nicole Figueiredo ${ }^{2}$
}

Este trabalho tem como objetivo inicial, descrever e analisar de que forma a experiência brasileira de combate à fome e à pobreza se tornou exemplo mundial, inspirando países a implementarem programas semelhantes. Em especial, busca-se explorar o trabalho do Centro de Excelência contra a Fome do Programa Mundial de Alimentos (PMA) na realização de cooperações técnicas Sul-Sul de combate à fome e à pobreza, sob a perspectiva da teoria da Policy Transfer. Também se pretende exemplificar quais têm sido os desafios e resultados alcançados em curto prazo, desde 2011 até o ano de 2016, na implementação dessas políticas em outros territórios, analisando o caso de um país em específico, Ruanda. Para tanto, foram examinados documentos oficiais disponíveis nas páginas eletrônicas da ONU, dos governos brasileiro e de Ruanda, além de declarações de fóruns e encontros internacionais. Foram realizadas duas entrevistas, além de uma análise bibliográfica selecionada sobre o tema. Conclui-se a importância que o Centro de Excelência contra a Fome tem tido no auxílio à disseminação de boas práticas brasileiras e, portanto, no combate à fome no mundo, e como sua existência tem sido fator determinante para que diversos países tenham acesso a este conhecimento e apoio.

Palavras-chave: Segurança Alimentar e Nutricional, Transferência de Políticas, Programa Mundial de Alimentos, Política Externa Brasileira, Centro de Excelência Contra a Fome, Cooperação Sul-Sul.

\section{The Brazilian food security and the World Food Programme}

This paper aims to describe and analyze how the Brazilian experience of fighting hunger and poverty has become a worldwide example, inspiring countries to implement similar programs. In particular, it seeks to explore the work of the Centre of Excellence against Hunger from the World Food Programme (WFP) for South-South technical cooperation in the fight against hunger and poverty, under the perspective of the Policy Transfer theory. Also, it attempt to exemplify what have been the short-term challenges and results achieved since 2011 and until 2016 on the implementation of these policies in other territories, analyzing the case of a specific country, Rwanda. For this purpose, official documents available on the UN web pages, and the Brazilian and the Rwandan government web pages were examined, as well as statements from international forums and meetings. Two interviews were conducted, as well as a bibliographical analysis selected on the topic. We conclude the importance that the Centre of Excellence against Hunger has had in helping the dissemination of Brazilian good practices and, therefore, in the fight against hunger in the world, and how its existence has been determinant for many countries to have access to this knowledge and support.

${ }^{1}$ Este trabalho sofreu alterações de sua primeira versão, que é fruto de um Trabalho de Conclusão de Curso de Nicole Figueiredo, graduada pelo curso de Relações Internacionais da Universidade Federal de São Paulo (UNIFESP). 2 Analista de Relações Internacionais pela Universidade Federal de São Paulo (UNIFESP) e mestranda em Políticas Públicas pela Universidade Federal do Paraná (UFPR). Endereço para correspondência: Rua Santos Dumont, no 1.306 - Maringá - PR. Telefone: (44) 99733-0356. E-mail. nicolefigueiredo@hotmail.com.br. 
Keywords: Food Security and Nutrition, Policy Transfer, World Food Programme, Brazilian Foreign Policy, Centre of Excellence Against Hunger, South-South Cooperation.

\section{INTRODUÇÃO}

O Brasil é um país que vem se destacando na última década por sua experiência bem-sucedida de combate à fome e à pobreza ${ }^{[1]}$. Tendo em vista isso, iniciou-se uma demanda por parte de países interessados em aprender com tais boas práticas ${ }^{[2]}$, além de um interesse do PMA e do próprio governo brasileiro, em criar uma nova agência deste programa no Brasil, com o intuito de facilitar a difusão destas experiências. Assim, surge em 2011 o Centro de Excelência contra a Fome do PMA, sediado Brasilia. Com seis anos de existência, o Centro de Excelência contra a Fome já realizou diversas atividades que serão exploradas mais à frente. Entre elas, atendeu a 38 países $^{3}$ auxiliando na disseminação das experiências bem-sucedidas vividas pelo Brasil na esfera de combate à fome e à pobreza.

Hoje no mundo ainda existem cerca de 795 milhões de pessoas que não possuem comida suficiente para terem uma vida saudável e ativa (2015), além de outros dados que chocam pela enorme dimensão que a fome ainda possui no mundo ${ }^{4}$. No caso brasileiro, as primeiras discussões em relação à segurança alimentar e nutricional (SAN) no âmbito governamental se dá por volta de $1940 \mathrm{com}$ a alimentação escolar ${ }^{[3]}$.

Dentre as principais iniciativas neste tema está o Programa Nacional de Alimentação Escolar (PNAE) em 1955, seguido do Conselho Nacional de Segurança Alimentar e Nutricional (CONSEA) em 1993, e a Lei de SAN de 2006. Outros programas de grande importância para as discussões de SAN no Brasil no pós-1940 e o papel destes na consolidação do histórico de políticas públicas serão abordadas em seguida, na parte de resultados e discussões do artigo.

Este trabalho tem como objetivo descrever e analisar a experiência do Centro de Excelência contra a Fome, frente à Teoria da Policy Transfer desenvolvida por Dolowitz e Marsh, que possibilitou um olhar mais específico para com os temas descritos e analisados. E discutir de que forma a experiência brasileira de combate à fome e à pobreza se tornou exemplo mundial, inspirando diversos países a implementarem programas semelhantes, somado a uma descrição da relação disto à Cooperação Sul-Sul.

Busca-se também ilustrar com o caso de Ruanda, quais têm sido os desafios e os resultados alcançados em curto prazo (desde 2011), da implementação dessas políticas em outros territórios, a fim de entender como vem ocorrendo o desenvolvimento dos projetos auxiliados pelo Centro de Excelência contra a Fome neste país.

É importante salientar que este estudo do caso de Ruanda não tem como objetivo chegar à conclusão alguma, ou análises mais profundas. Este estudo final tem como objetivo pura e simplesmente a descrição das etapas que ocorrem na cooperação Centro de Excelência contra a Fome para com outros países, na tentativa de tornar mais claro como esta cooperação se dá.

Há um grande aumento no número de processos de transferência de políticas na esfera internacional, mesmo não sendo um instrumento novo, esta prática tem se aprimorado cada vez mais, graças às tecnologias e aos meios de comunicação disponíveis na atualidade.

Mais recentemente, surgem também às discussões acerca de políticas públicas no sistema internacional, com o apoio do Banco Mundial, Fundo Monetário Internacional (FMI), entre outros organismos, que advogam a favor dos esforços relacionados à disseminação de boas práticas na política internacional[4].

Apesar da terminologia referente à política de transferência variar, quando se refere à expressão Policy Transfer, geralmente se trata de uma análise qualitativa,

${ }_{3}^{3}$ Dados disponiveis em: http://www.wfp.org/centre-of-excellence-hunger. Consultado em 16/11/2016.

${ }^{4}$ Estes e outros dados relacionados estão disponíveis em: https://wwww.wfp.org/hunger/stats. Consultado em 19/11/2016. 
descrevendo por meio do método de process-tracing 5 os casos de transferência, diferente da Policy Diffusion Studies, que realiza um estudo quantitativo[1]. Tal teoria foi criada com a intenção de ser uma estrutura heurística, que simplificasse o procedimento de análise e, como outras estruturas heurísticas, vêm sendo aprimorada ao longo do tempo para melhor compreender aspectos da elaboração de políticas[5]. Em seguida para um melhor entendimento da teoria listaremos seus principais conceitos e debates.

Dolowitz e Marsh organizam grupos de fatores que influenciam o processo de transferência para um estudo mais empírico e sistemático. Apontam quais seriam os possíveis agentes da Policy Transfer, quais os possíveis objetos de transferência de um sistema político para outro[ ${ }^{[]}$, e como se analisaria quando políticas de transferência são bem ou mal sucedidas ${ }^{[4]}$.

Para abordarmos uma das discussões primordiais do estudo da Policy Transfer, deve-se analisar porque os atores estão propensos a se engajar em uma transferência de política, entre outras alternativas existentes para resolver um problema político. Uma Policy Transfer pode ocorrer de forma voluntária, coercitiva direta, ou coercitiva indireta (que seria uma mistura dos dois extremos) ${ }^{[7]}$, e dentro disso, existem quatro níveis possíveis de transferência: cópia, emulação (adaptação), combinação e inspiração[1]. Somado a isso, deve-se levar sempre em conta que diferentes políticas/programas são resultado de diferentes motivações, e que isso varia de cada ator ${ }^{[4]}$.

\section{MÉTODOS}

Para tanto, foram examinados documentos oficiais disponíveis nos sites da ONU, do governo brasileiro e do governo de Ruanda, além de declarações de fóruns e encontros internacionais, uma análise bibliográfica selecionada sobre o tema, outros materiais citados na bibliografia deste artigo ou em nota de rodapé, e entrevistas semiestruturadas com o Diretor do Centro de Excelência contra a Fome (Daniel Silva Balaban) e com a Gerente de Cooperação Sul-Sul Trilateral com Organismos Internacionais da Agência Brasileira de Cooperação (ABC) (Cecilia Malaguti do

5 Proess-Tracing é uma forma de análise que faz meio de uma espécie de cronologia reversa, observando primeiro os resultados, a partir deles analisa as causas e os fatores que antecederam o fato. É uma análise profunda, que faz uso de aspectos históricos de complexidades causais para explicar os resultados. Neste caso, para analisar a existência do Centro de Excelência, é precis analisar os fatores que fizeram da história brasileira uma experiência bem-sucedida. Mais informações dispo 6 Prova deste fato é, o primeiro dentre as 8 Objetivos de Desenvolvimento do Milênio (ODM) da ONU estabelecidas em 2000 e adotadas por 189 Estados Membros da ONU, ser a questão de erradicar a fome e a pobreza extrema no mundo, e em 2015 com os novos 17 Objetivos de Desenvolvimento Sustentável (ODS), a erradicação da pobreza e a fome zero somada a uma agricultura sustentável, seguir sendo o primeiro e segundo objetivo de tais metas internacionais. Além do desafio Fome Zero (Zer
Prado), atores chave para a compreensão dos atuais esquemas de cooperação levados pelo Centro de Excelência contra a Fome e pela $\mathrm{ABC}$, em nome do governo brasileiro.

A segunda parte do artigo, desenvolvida após a descrição dos métodos, é composta dos resultados e discussões, contendo uma descrição da experiência brasileira de combate à fome e à pobreza e sua relação com a cooperação Sul-Sul, logo após descrever-se-á a experiência do Centro de Excelência contra a Fome, e de uma análise disto frente à teoria da Policy Transfer, somado a um estudo descritivo da cooperação técnica brasileira, via Cento de Excelência contra a Fome em Ruanda. E por fim as considerações finais e referências. Optou-se pelo recorte temporal 2011-2016 pelo ano de criação do Centro de Excelência contra a Fome (2011) e pela disponibilidade de dados até o ano de 2016.

Para análise da experiência do Centro de Excelência contra a Fome, neste artigo será utilizada a teoria da Policy Transfer elaborada por Dolowitz e Marsh[4,5,7]. É uma teoria que se coloca frutífera para este estudo, por tratar diretamente do tema que buscamos abordar (transferência de políticas), tornando mais clara qual a relação entre os conceitos citados pelos autores e o conteúdo abordado no artigo.

\section{RESULTADOS E DISCUSSÃO}

\section{A experiência brasileira de combate à fome e à pobreza e a cooperação Sul-Sul}

A SAN tem sido um assunto cada vez mais abordado no Sistema Internacional ${ }^{6}$ e o PMA tem desempenhado em todo o globo um papel fundamental para combater as situações de emergências existentes desde 1963[8]7. Vale mencionar que o Brasil também recebeu, até 1976, auxílio do PMA por meio de um projeto chamado "Programa de Alimentos para o Desenvolvimento" que visou atender crianças que faziam parte da faixa etária escolar e outras populações carentes ${ }^{[0]}{ }^{8}$. O que não se aplica mais aos dias de hoje, já que o Brasil se declarou autossuficiente neste quesito, dispensando a ajuda na questão alimentar por este

\footnotetext{
Humger Challenge) lançado pelo secretátio-geral da ONU Ban Ki-moon, e que tem como inspiração a experiência brasileira. Mais informaçốes disponiveis em: http://www.un.org/en/zerohunger/challenge.shtml. Consultado em 19/11/2016. em cada pais, disponivel em: httr: //data.devinit.ort. Consultado em 16/11/2016.

${ }_{8}$ Apesar disso, em 1991 o governo brasileiro junto ao PMA formula o decteto ñ 54 de 8 de marco de 1991, que prevê o regimento aplićável para quaisquer outras ajudas que possam vir a existir, divulgada no Diário Oficial da União, e é também apoiado neste

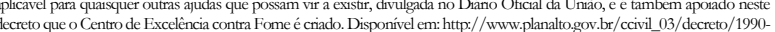
1994/D0054.htm. Consultado em 11/05/2016.
} 
órgão das Nações Unidas naquele momento. Apesar disso, o direito à alimentação só passou a constar na constituição federal no artigo $6 \underline{0}$ após a emenda constitucional n. 64 de $2010^{9}$, o que só é previsto em mais outros dois países do globo ${ }^{10}$.

A alimentação escolar, dentro do programa Fome Zero e dentre os temas de SAN, tem sido um dos mais importantes. Já que é capaz de somar ao mesmo tempo temas como a educação, nutrição e proteção social. Esse tipo de combate à fome tem alcançado grande sucesso por ser capaz de encorajar famílias de baixa renda a manter seus filhos na escola, trazendo hábitos alimentares mais saudáveis e nutritivos, o que contribui para a quebra do ciclo da fome, da pobreza, do baixo nível de escolaridade e da exploração de crianças em trabalho infantil. É uma forma eficiente de fazer com que a alimentação se torne um estímulo para os estudos, diminuindo o número de evasão nas escolas ${ }^{[10]}$. O PMA também utiliza esta tática de combate à fome, fornecendo alimentação escolar para 22 milhões de crianças, em mais de 60 países ${ }^{[8]}$.

No que tange ao combate à fome no Brasil, há um histórico de experiências com alimentação escolar desde a década de 1940 quando se lançou a proposta pelo governo federal de prover alimentação nas escolas. Com o passar dos anos, o programa recebeu diferentes nomes e passou a se expandir pelo território nacional, até que em 1972 houve a criação do Instituto Nacional para a Alimentação e Nutrição, vinculado ao Ministério da Saúde, que era responsável pelo chamado Programa Nacional de Alimentação Escolar. Ao longo do tempo, esse programa foi se aperfeiçoando, até que em 1979 se tornou o que hoje conhecemos por $\mathrm{PNAE}^{[3]}$.

A intensificação desta experiência de combate à fome e a pobreza se dá em especial a partir de 1993, com o Plano Nacional de Combate à Fome e a Pobreza e, paralelamente, com o surgimento do CONSEA, que representa um espaço de articulação entre governo e sociedade como forma de propor diretrizes e ações para a área de SAN. E, mais recentemente, dez anos depois (2003), com o programa Fome Zero, vê-se um plano de ação mais desenvolvido e estruturado. Trata-se de uma estratégia de combate à fome, composta por mais de 20 outras iniciativas dentro desta, que seriam: Programa Bolsa Família, alimentação escolar via PNAE, restaurantes populares, Programa Nacional de Fortalecimento da Agricultura Familiar, PAA, parcerias com a sociedade civil, entre outros ${ }^{[11]}$. E em 2011, o plano Brasil sem Miséria veio para integrar os programas sociais no Brasil ${ }^{11}$.

Com estas iniciativas do programa Fome Zero, vemos quatro principais pontos de abrangência: 1) acesso à comida; 2) desenvolvimento das próximas gerações, já que são programas de longo prazo que abrangem a questão educacional, geração de empregos e de combate à miséria; 3) fortalecimento da agricultura familiar ${ }^{12}$; e 4) articulação, mobilização e inclusão social $^{13}$, quando se trata de ter uma representatividade vinda da sociedade civil. Para melhor visualização da cronologia e os objetivos destes programas de SAN no Brasil, segue a tabela:
${ }^{12}$ Lei n n 11.947 de 2009: 30\% dos recursos repassados pelo Fundo Nacional de Desenvolvimento da Educação (FNDE) deverão ser utilizados na aquisição de alimentos vindos da agricultura familiar, empreendedor tural, assentamentos da reforma agrária, comunidades indigenas e quilombolas. Alem de prever o proprio direito a alimentação
www.planalto.gov.br/ccivi__03/_ato2007-2010/2009/lei/111947.htm. Consultado em: 12/05/2016.

13 Outros programas que estão relacionados com este ponto são: Centro de Referência da Assistência Social (CRAS), Programa de Atençăo Integral à Familia (PAIF), além de parcerias com o setor privado o o terceiro setor, e programas de educcá̃ó cidadã e de mobilização social. Disponivel em: http://www.ipc-undp.org/pub/IPCCountryStudy22.pdf Consultado em: 13/11/2016. 
Tabela 1. Principais políticas e/ou programas do arcabouço de SAN no Brasil

\begin{tabular}{|c|c|c|}
\hline Ano de criação & Política ou Programa & Objetivo principal \\
\hline 1955 & $\begin{array}{l}\text { Programa Nacional de Alimentação Escolar } \\
\text { (PNAE) }\end{array}$ & $\begin{array}{l}\text { Transferência de recursos financeiros do Governo Federal aos municípios e } \\
\text { estados, para a aquisição de alimentos destinados à merenda escolar. }\end{array}$ \\
\hline 1993 & $\begin{array}{l}\text { Conselho Nacional de Segurança Alimentar e } \\
\text { Nutricional (CONSEA) }\end{array}$ & $\begin{array}{l}\text { Espaço institucional para a participação social na formulação, monitoramento e } \\
\text { avaliação de políticas públicas de segurança alimentar e nutricional. }\end{array}$ \\
\hline 1996 & $\begin{array}{l}\text { Programa Nacional de Fortalecimento da } \\
\text { Agricultura Familiar (PRONAF) }\end{array}$ & $\begin{array}{l}\text { Financiamento que visa a geração de renda e o aprimoramento da mão de obra } \\
\text { familiar nas áreas rurais, via modernização, industrialização e ampliação das } \\
\text { estruturas de produção e de serviços relacionados. }\end{array}$ \\
\hline 2003 & Fome Zero & $\begin{array}{l}\text { Integração política de estruturas no combate à fome e a à pobreza em um âmbito } \\
\text { emergencial. }\end{array}$ \\
\hline 2003 & $\begin{array}{l}\text { Programa de Aquisição de Alimentos da } \\
\text { Agricultura Familiar (PAA) }\end{array}$ & Promoção do acesso à alimentação e incentivo à agricultura familiar. \\
\hline 2004 & Bolsa Família & $\begin{array}{l}\text { Programa de transferência direta da renda, voltado a famílias em situação de } \\
\text { pobreza ou extrema pobreza. }\end{array}$ \\
\hline 2005 & Sistema Único de Assistência Social (SUAS) & $\begin{array}{l}\text { Proteção social aos cidadãos por meio de serviços, benefícios, programas e } \\
\text { projetos. }\end{array}$ \\
\hline 2006 & Lei de Segurança Alimentar e Nutricional & $\begin{array}{l}\text { Estabelecer definições, princípios, diretrizes e objetivos do Sistema Nacional de } \\
\text { Segurança Alimentar e Nutricional (SISAN). }\end{array}$ \\
\hline 2011 & Brasil sem Miséria (BSM) & $\begin{array}{l}\text { Retirar a população da extrema pobreza via: garantia de renda, acesso aos } \\
\text { serviços públicos e inclusão produtiva no mercado de trabalho. }\end{array}$ \\
\hline
\end{tabular}

É notável que para que um arcabouço de tamanha dimensão de programas interligados funcione dentro do esperado, num país de dimensões como o Brasil, faz-se necessária a participação de diversos ministérios e dos níveis federal, estadual e municipal[12]. Em relação a esta articulação existente para que a SAN ocorra no Brasil e o papel da sociedade civil neste meio, Daniel Silva Balaban ${ }^{[13]}$ cita:

As políticas sociais brasileiras foram criadas através de um arcabouço intersetorial, tanto é que existe a câmara intersetorial de segurança alimentar e nutricional ${ }^{14}$, no qual vários ministérios estão envolvidos e tem representação lá. Significa que todas as políticas estão interligadas, e cada política precisa da ação de diferentes ministérios. Por exemplo, o bolsa família foi feito para que as famílias enviassem e mantivessem as crianças na escola, significa que é o ministério da educação responsável, o bolsa familia em si, é o ministério do desenvolvimento social responsável, e as famílias também devem atender às campanhas de vacinação, que quem faz é o ministério da saúde, os pequenos agricultores envolvidos também, é o ministério do desenvolvimento agrário. Então você vê que uma única ação possui três ou quatro ministérios envolvidos que tem que trabalhar em conjunto. O papel da sociedade civil é importantíssimo dentro disso, porque a sociedade civil é que faz com que as políticas funcionem. $\mathrm{O}$ Brasil é um país muito grande, com várias diferenças, então é impossível que o governo consiga controlar tudo que acontece na ponta, e quando tem a sociedade civil atuante e trabalhando junto, é mais fácil de saber o que está acontecendo, porque eles estão vivendo na ponta, eles sabem dos problemas que são enfrentados, eles têm de repente soluções para estes problemas.

Ressaltando o papel do governo no combate à fome e à pobreza, cito também a contribuição feita por José Graziano da Silva e Maya Takagi[14], no Seminário Nacional de Segurança Alimentar e Nutricional do Partido dos Trabalhadores em 2003:

A pobreza é um fenômeno não apenas estatístico e biológico, mas também político. Não significa apenas um atraso no acesso aos bens de consumo, mas também a privação da cidadania. Ela é a consequência estrutural de um modelo de 
desenvolvimento perverso, que gera privilégios e privações (p.51).

Dentro deste arcabouço institucional citado, se soma em 2006 a Lei de SAN (Lei no 11.346 de 15 de setembro de 2006), que em seu artigo 6o cria a obrigação legal do Estado brasileiro dedicar-se na promoção de cooperação com outros países, promovendo assim o direito humano à alimentação, também no plano internacional[15]. Isto é, transmite-se por meio de prerrogativa legal o papel brasileiro no Sistema Internacional e principalmente em suas ações no "Sul Global".

Além disso, pode-se também incluir nesse papel brasileiro as ações feitas em conjunto com o IBAS (Fórum de Diálogo Índia, Brasil e África do Sul), MERCOSUL (Mercado Comum do Sul) e CELAC (Comunidade dos Estados Latino-americanos e Caribenhos).

No caso do IBAS, as ações neste âmbito se baseiam no Fundo IBAS para Alívio da Fome e da Pobreza $^{15}$, que desde 2004 financia projetos de países em desenvolvimento voltados ao alívio da fome e da pobreza. Referente ao bloco MERCOSUL encontra-se em sua agenda de trabalho a busca pelo direito humano à alimentação adequada nos países participantes do mercado comum, além da questão da inclusão da agricultura familiar e camponesa. Sobre este tema no cenário internacional, há comprometimento em levar tais questões a instituições como a Cúpula da América Latina e do Caribe e União das Nações Sul-americanas, por parte dos países membros do MERCOSUL ${ }^{16]}$.

E no tocante à CELAC, integra a este grupo de ações o projeto "América Latina e Caribe sem Fome", em parceria com a FAO, onde os integrantes da Comunidade se comprometeram a erradicar a fome até o ano de $2025^{16}$ Iniciativas também como o Mundo sem Pobreza (World Without Poverty - WWWP) ${ }^{17}$, em parceria com o Banco Mundial, governo brasileiro e IPC-IG do PNUD (Centro Internacional de Políticas para o Crescimento Inclusivo do Programa das Nações Unidas para o Desenvolvimento), fazem parte de ações brasileiras que visam apoiar o aprendizado para a

${ }^{15}$ Cada um dos países participantes destina por ano um milhão de dólares ao fundo, e os recursos são direcionados ao Escritório de Cooperação Sul-Sul das Naçōes Unidas. Disponivel em: http://www.itamaraty.gov.br/pt-BR/component/tags/tag/336de Cooperaçăo Sul-Sul das Nações Unì

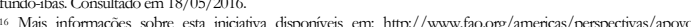
Consultado em: $19 / 11 / 2016$

${ }^{17}$ Disponivel em: http://www.wwp.org.br. Consultado em 19/11/2016

${ }^{18}$ Quando mencionamos o conceito de segurança alimentar, cabe tmzer também o conceito de segurança alimentar mencionado na Conferência Mundial de alimentação (World Food Summit) em 1996: "Segurança alimentar existe quando todas as pessoas, toda hora, têm acesso físico e econômico a uma quantia suficiente de alimentos, seguros e nutritivos que atendam à sua inovação de programas que respondam positivamente ao combate à fome e à pobreza no mundo.

E dentro desta lógica surge a cooperação SulSul no âmbito da SAN ${ }^{18}$ abordada neste artigo, em que o Brasil soma sua experiência de combate à fome e a pobreza com a presença e a experiência do PMA da $\mathrm{ONU}^{19}$. E, portanto, é nesse contexto que se dá a criação do Centro de Excelência contra a Fome. Expondo todos esses pontos, da experiência brasileira, e do florescimento deste tema de Cooperação Sul-Sul na política externa brasileira, se torna mais claro o porquê da ligação entre estes pontos. Verifica-se um alinhamento das políticas públicas brasileiras e da política externa, como uma das formas do Brasil exercer a cooperação para o desenvolvimento no cenário internacional.

Apesar de o Brasil não ter números muito significantes quando se trata de doações em assistência humanitária, é um país de importância estratégica, desde o fato de ter sido receptor e doador de assistência humanitária em uma única década, ser um ator que possui relativa importância no cenário internacional, por uma crescente influência em grupos políticos como os BRICS, e também por desenvolver importante papel em operações de peacekeeping da ONU. Ademais, seu exemplo positivo no fato de reduzir quase $3 / 4$ da extrema pobreza em poucos anos, e após isso ter liderado diversas ações de Cooperação Sul-Sul para compartilhar suas experiências, por demanda dos países interessados, tem colocado o país como ator de alto poder brando (soft power) em temas de assistência social[2].

Em 2003, quando novas práticas políticas foram incorporadas à política externa brasileira, o Sul Global, passou a ser um ponto central na formulação desta política externa. Neste aspecto, o Brasil se coloca como um país disposto à criação de mecanismos que fomentam o diálogo e a cooperação como questões relevantes para uma mudança do Sistema Internacional. Além do que, com um interesse de fortalecer sua capacidade de negociação com países desenvolvidos, o Brasil busca combinar seu desenvolvimento nacional e projetar seus interesses para o mundo, tentando utilizar

necessidades dietéticas e preferências alimentares para uma vida ativa e saudável" (tradução livre), Disponível em: http://www.fao.org//forestry/13128-0e6f36f27e0091055bec28ebe830f46b3.pdf (p.1). Consultado em 18/11/2016. 19 Frisando a importancia da segurança alimentar para todos os Estados, a Declaraçáo de Roma sobre a Segurança Alimentar Mundial (W orld Food Summint) de $1996 \mathrm{em}$ seu ponto 54 , declara. $\mathrm{A}$ segurança alimentar mundial é do interesse de todos os
membros da comunidade internacional, devido à sua crescente interdependência com as questôes da estabilidade políica e da paz, erradicação da pobreza, prevenção e reação a crises e catástrofes, degradação do meio ambiente, comércio, ameaças mundiais à̃ sustentabilidade da segurança alimentar, çescimento demográfico, movimentos fronteiriços da populaç̃o, bem como tennologia, pesquisa, investimento, financiamento e cooperação." Declaração de Roma sobre a Segurannça Alimentar Mundial está disponivel $\mathrm{em}$ : http://www.fao.org/docrep/003/W3613P/W3613P00.htm. Consultado em 20/11/2016. 
um papel de Global Player, que intervém na dinâmica internacional e auxilia no desenvolvimento dos países do "Sul"[17].

\section{Análise e descrição da experiência do Centro de Excelência contra a Fome}

Sobre as políticas públicas estatais, nas últimas duas décadas, há o surgimento de um novo fenômeno global, que registra o aumento no número de países que passaram a introduzir políticas de proteção social em seu território, seja na Âfrica, América Latina ou Ásia. Tal fato possui ligação com o aumento no número de redes de política internacional, no que se refere às que possuem como objetivo também a facilitação da troca de experiências em proteção social.

Neste sentido, notou-se que estes esforços conjuntos contribuem para a mudança de políticas domésticas em alguns países, evitando, por sua vez, a coerção internacional que ocorria para que estes países adotassem medidas econômicas e/ou sociais, tornando essa adoção de medidas uma ação voluntária, ou até mesmo uma mistura dos dois, o voluntariado e a coerção, dependendo dos elementos presentes ${ }^{[1]}$.

Em âmbito internacional, o protagonismo brasileiro pela experiência em programas sociais bemsucedidos, e o interesse da ONU e de outros países por essa experiência, concebe ao governo brasileiro ${ }^{20}$ a oportunidade de criar em parceria com o $\mathrm{PMA}^{21}$, o Centro de Excelência contra a Fome, um fórum global Sul-Sul de diálogo e de aprendizado de SAN, alimentação escolar e programas correlatos de erradicação da pobreza. Criado em 2011, este programa busca somar o conhecimento de mais de 50 anos do PMA e a experiência de sucesso do governo brasileiro com os programas já citados.

Este esquema de cooperação executado pelo Centro de Excelência conta a Fome é chamado de trilateral, isso se justifica pela cooperação ser composta por uma organização internacional, e dois outros Estados que integram o esquema (Brasil e outro país, neste caso), ou na possibilidade de um dos Estados serem substituídos por uma rede de advocacy (exemplo do caso da Rede Africana de Alimentação Escolar, citada mais à frente), entre outras possíveis combinações ${ }^{22}$.

O PMA é uma agência que possui escritórios em mais de oitenta países e tem como objetivo principal erradicar a fome e a desnutrição, principalmente em situações de emergência, como as encontradas em campos de refugiados, com populações em situações críticas e em momentos de vulnerabilidade. Em segundo plano, o objetivo do PMA tem sido a implementação, em longo prazo, de sistemas/programas autônomos que combatam eficazmente a questão da insegurança alimentar e diminuam a dependência, o que seria o papel do Centro de Excelência contra a Fome[18,19].

Como consequência à grande efetividade do Brasil neste campo que o PMA busca exercer em longo prazo, a parceria entre o governo brasileiro e este organismo internacional se torna possível, levando a experiência e o conhecimento brasileiro em tal área para outros Estados por meio do Centro de Excelência contra a Fome, tendo sempre em conta as especificidades de cada país. O que faz com que experiências mal sucedidas de política de transferência sejam evitadas ao máximo pelo Centro de Excelência contra a Fome e pelo governo brasileiro, de acordo com os critérios de uma má experiência de transferência de políticas na teoria da Policy Transfer (transferência não informada, transferência incompleta e transferência inapropriada).

Sobre a função do Centro de Excelência, segue a fala do Diretor do Centro de Excelência contra a Fome, Daniel Silva Balaban no relatório anual de 2015[20]:

O trabalho de cooperação Sul-Sul realizado pelo Centro contribui para acelerar processos de transformação social ao apoiar a criação de políticas nacionais sustentáveis de proteção social, como políticas de alimentação escolar e de fomento à agricultura familiar (...). O fomento a redes regionais de colaboração foi provavelmente o ponto alto do trabalho do Centro em 2015 e certamente continuará sendo em 2016. (p. 04-05) 
Sobre as redes regionais de colaboração citado por Daniel Silva Balaban[13], encontra-se o exemplo da Rede Africana de Alimentação Escolar ${ }^{23}$, lançada em junho de 2015:

\begin{abstract}
As redes vêm para incrementar e fortalecer o apoio que o país dá bilateralmente, o apoio que o Centro dá bilateralmente com determinados países. Quando você tem uma rede, você faz com que todos os países possam se comunicar, possam entender seus problemas, possam verificar soluções novas e possam se integrar então todas as redes são benéficas, porque a rede vai facilitar inclusive o trabalho do Centro, que não é eterno, seu trabalho é fazer com que os países tenham uma força para começarem a criar políticas e depois não precisem mais de nós, e as redes fazem com que eles evoluam e se desenvolvam, porque através das redes cada um vai saber o que os outros estão fazendo, vão saber aonde erraram e acertaram os exemplos de outros países(...). Então as redes são fundamentais para que haja a plenitude dos trabalhos e que esses trabalhos sejam sustentáveis ao longo do tempo, sem que precise que o Centro ou um organismo internacional fique eternamente ajudando um país. Ele se desenvolve, ele começa, ele cria e ele vai em frente, e as redes fazem com que eles tenham uma sustentabilidade maior.
\end{abstract}

O maior e mais recente exemplo de rede que veio para somar na luta contra à fome é a Rede Africana de Alimentação Escolar ${ }^{24}$, aprovada por 21 países, têm como objetivo o compartilhamento de experiências e o fortalecimento de programas nacionais de alimentação escolar, e como parte da difusão destas políticas, a União Africana que integra 54 países, também foi envolvida no projeto, dando assim maior dimensão à Redel[20].

Outro fórum que busca debater e apoiar a alimentação escolar e a nutrição infantil com diferentes governos, ONGs, empresas e profissionais da área, é o Fórum Global de Nutrição Infantil (The Global Child Nutrition Forum - GCNF) ${ }^{25}$, que acontece anualmente desde 1997, mas que nos últimos anos ganhou também o apoio do Centro de Excelência contra a Fome. Este fórum inclusive foi uma plataforma de diálogo para a criação da própria Rede Africana de Alimentação Escolar.
Referente à teoria da Policy Transfer e as redes, vale perceber que as motivações dos países participantes desta são semelhantes, por isso buscam políticas e soluções parecidas aos seus problemas, os quais também se assemelham.

O Centro de Excelência contra a Fome, em parceria com o governo brasileiro, é um espaço em que governos e autoridades da África, Ásia e América Latina fomentam suas práticas, acompanhados das experiências brasileiras de políticas sociais.

Entre as principais políticas brasileiras, estão: o programa Bolsa Familia e Fome Zero, juntamente com a alimentação escolar sustentável, a agricultura familiar, além de mecanismos legais, institucionais e financeiros, criados para apoiar estratégias de combate à fome e à miséria. Sendo assim, discute-se de que forma tais experiências poderiam inspirar a formação de novos programas nestes países, observando obviamente as diferenças e particularidades existentes em cada país, como dito anteriormente, já que a intenção não é meramente replicar a experiência brasileira, mas sim sugestionar a realização de projetos semelhantes e mostrar exemplos de sucessos, os quais podem ser inspiração para outros países do Sul global[21].

Levando em conta a teoria da Policy Transfer, estas experiências de transferência podem ser desde a chamada emulação, inspiração, ou até a combinação, mas nunca uma transferência integralmente copiada. Já que tal conceito varia de acordo com o que cada país busca, e até que ponto as experiências brasileiras lhe servem à sua realidade.

Diferentemente de outros escritórios da ONU, o Centro de Excelência contra a Fome tem a função de servir como plataforma para uma cooperação Sul-Sul e não Norte-Sul, como costuma acontecer em ajudas humanitárias feitas pela $\mathrm{ONU}^{26}$. Trata-se do único escritório do PMA que possui esse âmbito diferenciado de cooperação, inspirado na experiência doméstica de um país, neste caso, a SAN brasileira ${ }^{27}$. 
Inicialmente, foi dada uma maior atenção por parte do Centro de Excelência contra a Fome a 18 países, considerados países de risco e prioritários para a ajuda: Timor-Leste, Guiné-Bissau, Haiti, Quênia, Malauí, Mali, Moçambique, Tanzânia, Gana, Laos, Ruanda, Senegal, Togo, Zâmbia, Bangladesh, Costa do Marfim, Nigéria e Zimbábue [21]. Ou seja, estes foram os primeiros países a terem o foco para serem atendidos pelo Centro de Excelência contra a Fome em 2011, mas não exclusivamente os únicos. Uma vez que estes países já foram atendidos, buscou-se atender às solicitações feitas por outros países em desenvolvimento que demonstraram interesse pelo sucesso que o Centro de Excelência contra a Fome vem tendo ${ }^{[21]}$.

O trabalho do Centro de Excelência contra a Fome com cada país tem início primeiramente com o pedido por parte desse país em conhecer a experiência brasileira (com exceção dos 18 países prioritários). Após isso, é possível marcar a realização de visitas de estudo no Brasil às delegações, além de workshops e reuniões, que visam ajudar os tomadores de decisão de cada país a terem maior contato com a sociedade brasileira, tendo, portanto, uma visão bem clara do papel da sociedade e qual sua visão dos programas sociais ${ }^{[8]}$.

Sendo assim, no tocante à teoria da Policy Transfer, o Centro de Excelência contra a Fome procura que as transferências sejam do tipo voluntário, quando o próprio país entra em contato com o Centro de Excelência demonstrando interesse em conhecer a experiência brasileira, ou no caso de ser uma transferência coercitiva indireta, quando os países são motivados por necessidade e porque já há previamente o envolvimento de uma organização internacional, que é o PMA e que já está presente na maioria dos países atendidos pelo Centro de Excelência, o que cria de certa forma uma pressão internacional para com estes países.

Tais visitas de estudo são a ferramenta inicial e fundamental para o começo da aprendizagem utilizada pelo programa, abrangendo a apresentação de agricultura familiar, por meio de assentamentos e cooperativas, além de nutrição, por meio de visita a restaurante comunitário e à Companhia Nacional de Abastecimento (CONAB), e também visitas a escolas para aprendizagem sobre a alimentação escolar no Brasil.

Ainda no que se refere à tais visitas, abordamse os subsídios, direitos e deveres previstos na legislação brasileira, do arcabouço que abrange a agricultura familiar, alimentação escolar e programas sociais, englobando diferentes populações, por meio de programas como: Programa de Aquisição de Alimentos (PAA), Programa Nacional de Alimentação Escolar (PNAE), Programa de Alimentação Pública e Abastecimento (PAPA), Empresa de Assistência Técnica e Extensão Rural (EMATER), Empresa Brasileira de Pesquisa Agropecuária (EMBRAPA), Conselho Nacional de Segurança Alimentar e Nutricional (CONSEA), entre outros ${ }^{[21]}$.

Após esta visita, as delegações já possuem maior conhecimento e ideia de como a experiência brasileira funciona, para diante disso analisar as diferenças e especificidades que seus países possuem e, assim, dispor de uma maior capacidade para criar o plano de ação, que será o esboço de um futuro programa à ser apresentado em seu país de origem. É o momento em que as delegações planejam as propostas que levarão aos seus países, fazendo isso com base nas lições que aprenderam na prática ${ }^{[1]}$.

O Centro de Excelência contra a Fome tem buscado manter um papel de consultor internacional em cada país que atende, acompanhando os desdobramentos do desenvolvimento das políticas em cada Estado, após realizarem a visita de campo com seus representantes no Brasil. E uma vez que se defina o que buscam concretizar em seu território, é oferecido o trabalho de apoio continuado ${ }^{[22]}$, que consiste em uma série de atividades de auxílio aos países interessados, garantindo assim que as próximas fases entre o planejamento e a execução dos programas também se tornem experiências de sucesso.

Segundo Buani ${ }^{18]}$ (p. 265-266), alguns fatores são basilares para que haja um bom e duradouro funcionamento dos programas sociais de combate à fome, e que são capazes de afetar positiva e negativamente a execução e o seguimento dos programas. Estas principais causas foram elencadas pela equipe de projetos do Centro de Excelência contra a Fome. São elas: referente ao campo político e legal: 1) é necessária uma estrutura legal que garanta a continuidade dos programas, mesmo quando ocorrem mudanças políticas; 2) além de uma grande disseminação das vantagens que tais programas trazem em longo prazo, para que haja grande comprometimento e vontade política. Referente ao financeiro é preciso: 1) mobilização de recursos do 
orçamento disponível; e 2) um grande controle de gastos e de transparência destes valores.

No âmbito institucional e de coordenação, é de grande utilidade: 1) expor as instituições a experiências que reforcem sua capacidade institucional em longo prazo; 2) ter a disposição mecanismos que permitam o diálogo entre distintos níveis governamentais e de coordenação das instituições; 3) além de uma forte ligação de diferentes programas da mesma esfera, como programas educacionais, de saúde, agricultura e desenvolvimento social, e também dispositivos capazes de monitorar estes diferentes campos. E finalmente, uma sensibilidade e atuação da comunidade também são condições favoráveis para a garantia de um bom funcionamento dos programas ${ }^{18]}$.

No tocante dos resultados, a FAO e o Departamento para o Desenvolvimento Internacional do Reino Unido (DFID), também têm tido grande colaboração. Podemos elencar como exemplo de bons resultados, projetos como o que os governos africanos vêm realizando: o PAA África (Purchase from Africans for África), inspirado no PAA do Brasil, e que promove assistência alimentar à Etiópia, Malauí, Moçambique, Níger e Senegal[21]28.

E junto ao conceito de Compras para o Progresso (P4P - Purchase for Progress), criado em 2008 pelo PMA, que tem como objetivo inserir o pequeno agricultor no mercado, e que foi inspirado na experiência brasileira de compras institucionais, $\mathrm{O}$ programa vem sendo somado ao PAA África, em Moçambique, Etiópia e Malaui, fortalecendo estes temas em território nacional[23].

Neste processo final, o PMA busca um acompanhamento contínuo com os países atendidos através da Cooperação técnica brasileira em matéria de SAN, por meio de deslocamento de consultores e missões de apoio, para garantir o sucesso da fase de formulação e execução dos projetos ${ }^{[22]}$.

Como resultado destes seis anos de trabalho, o Centro de Excelência contra a Fome em parceria com o governo brasileiro já atendeu 38 países diferentes em 48 visitas de estudos realizadas no Brasil, além de 25

Consultado em $13 / 11 / 2016$.

${ }^{29}$ Dados disponiveis em: http://www.wff.org/centre-of-excellence-hunger. Consultado em 16/11/2016. 30 Disponivel em: hittps://wwww.facebook.com-nototes/wfp-centre-of-excellence-against-hunger/centro-inicia-avaliação-de-
impacto/664870373650924. Consultado em 14/11/2016. missões técnicas a 18 países e apoio a 25 países na formulação e na implementação de programas de combate à fome sustentáveis ${ }^{29}$. Ainda são necessárias mais ações para acabar com a fome no mundo, mas é inegável a diferença que este organismo tem feito no combate à fome e à pobreza em diversos países.

\section{Cooperação técnica Brasil-Ruanda via Centro de Excelência contra a Fome: análise de uma experiência recente}

Este estudo de caso tem a intenção de ilustrar como funciona o trabalho do Centro de Excelência contra a Fome com outros países, detalhando em uma experiência real quais as etapas seguidas quando um país demanda a ajuda deste organismo, além da cooperação técnica brasileira nesta estrutura. Diante disso, escolheu-se esmiuçar o caso de Ruanda, por ser um país que começou a trabalhar com o tema de combate à fome e a pobreza inspirado na experiência brasileira, desde o surgimento do Centro de Excelência.

Vale deixar claro que este estudo não pretende chegar a nenhum resultado específico no que se refere a medir as consequências e a repercussão dos programas, já que é uma experiência relativamente recente. O próprio Centro de Excelência contra a Fome começou apenas em março de 2016 a medir os primeiros impactos de suas ações ${ }^{30}$. Assim, ainda não há material disponível e acessível para realizar um estudo mais profundo. Logo, busca-se exemplificar para um melhor entendimento de que forma se concretiza a cooperação de caráter triangular, considerando uma experiência concreta que envolve Brasil, Ruanda e o Centro de Excelência contra a Fome.

O caso de Ruanda não é o mais antigo no quesito inspiração na experiência brasileira e talvez não seja o país que possui um maior grau de desenvolvimento em seus programas sociais, entre os que contam com a parceria do Centro de Excelência contra a Fome ${ }^{31}$. Temos o caso de Moçambique, por exemplo, que bilateralmente desde o ano de 2010 conta com a cooperação brasileira para a elaboração de programas de combate à fome e a pobreza ${ }^{32}$, mas esta relação Brasil-Moçambique se deu primeiramente de forma bilateral, e somente em segundo momento
Não há nenhuma intenção em comparar o nível de desenvolvimento que cada pás tem em seus programas de combate à fome

è̀ pobreza.
32 “(...) desde 2010 o governo brasileiro desenvolveu uma ação com Mocambique e o PMA de Moçambique, nós assinamos um memorando de entendimento, onde o PMA de Moçambique disponibilizaria tantos milhöes, e o governo brasileiro tantos milhōes mais a capacidade técnica para estabelecer lá um programa de alimentação escolar, e isso foi feito"’’łn 
houve a inserção do Centro de Excelência contra a Fome para auxiliar nos programas.

O que se optou neste artigo foi a abordagem de um caso em que a relação brasileira com outro país, no quesito programas de combate à fome e à pobreza, se desse desde o início com a participação do Centro de Excelência contra a Fome, por isso a escolha de Ruanda. Este estudo busca explorar as atividades desse organismo nos últimos cinco anos, com o objetivo de discutir seu impacto nas relações de cooperação técnica brasileira com tal país e, descrever a importância da atuação do Centro de Excelência contra a Fome no combate à fome e à pobreza em diversos países.

O PMA está em Ruanda desde 1972, primeiramente com o Programa "Alimento por Trabalho" (Food for Work), que conta com a ajuda da comunidade local em trabalhos que visam a construção e o melhoramento da infraestrutura do país, e o pagamento é feito em comida. Logo após, no ano de 2001 o PMA auxilia também na Alimentação Escolar de Ruanda, e na instalação do programa Compras para o Progresso (P4P). Ainda em relação ao P4P, o Ministério da Agricultura e Recursos Animais de Ruanda em parceria com este programa emitiu um Decreto Ministerial que previa que em média $60 \%$ das necessidades alimentares de escolas e instituições governamentais, fossem fornecidas por meio de compras de pequenos agricultores ${ }^{[18]}$.

Entre os 18 países elencados como prioritários pelo Centro de Excelência contra a Fome e pelo governo brasileiro se encontra Ruanda, como citado anteriormente. Sendo assim, o contato entre o Centro de Excelência e Ruanda se deu desde o início da existência deste organismo no Brasil.

Mais especificamente, em abril de 2012, há relatos feitos pelo Centro de Excelência contra a Fome sobre a visita de estudos realizada pela delegação ruandesa, integrada também pelo até então primeiroministro de Ruanda, Pierre Habumuremy[21]. Como de praxe, após esta visita foi realizado o plano de ação, em que a delegação de Ruanda elaborou as propostas e as ideias de ações no combate à fome e à pobreza, o que foi levado para ser discutido com o governo e a sociedade ruandesa.

Ainda no ano de 2012, em maio e outubro, foram realizadas análises junto ao PMA de Ruanda e aos ministros do país, que avaliaram o custo-benefício dos programas que vinham sendo elaborados até então, paralelo a uma missão de apoio que ocorreu também no segundo semestre de 2012, missão a qual, buscou realizar uma assessoria técnica continuada após a visita de estudos ${ }^{[21]}$.

Logo após, em 26 e 27 de fevereiro de 2013, foi realizado o seminário em Ruanda que teve por objetivo discutir o que foi idealizado no Plano de Ação e, ao mesmo tempo, criar um ambiente político para que fossem discutidas as propostas de combate à fome e à pobreza[22].

Para que tais discussões ocorressem houve uma grande mobilização nacional, com a participação de representantes ruandeses dos trinta distritos, governadores das quatro províncias, ministros de seis diferentes áreas, além da participação da sociedade civil, ONGs, associações, entre outros ${ }^{[18]}$. O que foi de extrema utilidade para a mobilização e conscientização de toda a sociedade ruandesa.

O planejamento do seminário teve a ajuda também do Centro de Excelência contra a Fome e do governo brasileiro. Entre os tópicos discutidos, estiveram: ${ }^{33}$ a necessidade do Programa Nacional de Alimentação Escolar ser flexível no que tange a adequar-se às diferentes realidades de Ruanda; que cada parte envolvida na execução tenha claro seus papéis e responsabilidades; necessidade de um financiamento sustentável ao programa e da promoção de parcerias; identificar possíveis lacunas existentes nas instituições, fortalecendo os arranjos que fazem parte do planejamento; importância da criação de um comitê que funcione como um sistema de monitoramento em nível nacional e multissetorial, assegurando a qualidade dos serviços e garantindo que o programa ocorresse de forma eficaz e sustentável; mobilização da comunidade, para que haja um engajamento; empoderamento e reconhecimento do programa como legítimo por parte da população, entre outros pontos discutidos ${ }^{[25]}$.

${ }_{33}$ Um relatório sobre o que foi discutido no seminário também pode ser encontrado online, disponível em: https://brazilcentreofexcellence.files.wordpress.com/2013/12/wfi_livrorwanda_teport2_final1.pdf. Consultado em 
Após esse seminário, continuaram a ser registradas ações de continuidade dos programas. Ainda em 2013, o Centro de Excelência contra a Fome enviou consultores para Ruanda com o intuito de auxiliar na criação e no desenvolvimento de políticas e programas previamente discutidos no plano de ação e no seminário[22].

Após esse momento de articulação e preparação, em 2014, Ruanda adotou um documento orientador para a alimentação escolar no país, com a participação do Ministério da Educação e da produção local de alimentos, além de lançar neste mesmo ano um projeto piloto que orienta a compra local de alimentos ${ }^{[8]}$. Em novembro de 2015, a delegação ruandesa retornou ao Brasil para a $\mathrm{V}$ Conferência Nacional de Segurança Alimentar e Nutricional, e nesta mesma oportunidade, o Centro de Excelência contra a
Fome aproveitou para promover diversas visitas à delegação de Ruanda e outras delegações que vieram ao evento, para melhor conhecimento de como funcionam cooperativas de agricultores familiares, restaurantes comunitários, banco de leite humano, entre outros ${ }^{[20]}$.

Vale citar que pós-2015 não houve publicações de mais ações em conjunto do governo de Ruanda e do Centro de Excelência contra a Fome, mas ainda assim o PMA segue com seus programas - de alimentação escolar, SAN, assistência à refugiados, redução de riscos e desastres naturais, e acesso de pequenos agricultores ao mercado ${ }^{34}$ - em Ruanda. Para melhor visualizar as iniciativas citadas, segue uma tabela que organiza de forma cronológica cada ação que o Centro de Excelência contra a Fome trabalhou em conjunto com o governo e/ou com o PMA de Ruanda:

Quadro 1: Cooperação técnica Brasil-Ruanda via Centro de Excelência contra a Fome

\begin{tabular}{|c|c|c|}
\hline Ano & Etapa Desenvolvida & Objetivo Principal \\
\hline 2011 & $\begin{array}{l}\text { Delimitação de } 18 \text { países prioritários, dentre } \\
\text { eles Ruanda. }\end{array}$ & $\begin{array}{l}\text { Na criação do Centro de Excelência contra a Fome foram delimitados países } \\
\text { prioritários para a ação deste organismo. }\end{array}$ \\
\hline Abril/2012 & $\begin{array}{l}\text { Visita de estudo multissetorial da delegação } \\
\text { de Ruanda no Brasil. }\end{array}$ & $\begin{array}{l}\text { Iniciou-se a capacitação da delegação de Ruanda via visita de estudo e } \\
\text { desenvolvimento do plano de ação. }\end{array}$ \\
\hline Maio/2012 & $\begin{array}{l}\text { Análise custo-benefício e GCNF (Fórum } \\
\text { Global de Nutrição Infantil). }\end{array}$ & $\begin{array}{l}\text { Elaboração da análise de custo-benefício com o apoio do PMA em relação ao } \\
\text { plano de ação. Além de uma discussão que visava aumentar o apoio técnico para } \\
\text { uma transição sustentável dos programas que o PMA vinha implementando } \\
\text { para os que compunha o novo plano de ação. Representantes do PMA de } \\
\text { Ruanda também participaram do GCNF na Etiópia. }\end{array}$ \\
\hline Agosto/2012 & Missão de apoio/acompanhamento. & $\begin{array}{l}\text { Acompanhamento com representantes de alto nível, visa facilitar o diálogo de } \\
\text { políticas e prestar acessória técnica. }\end{array}$ \\
\hline Outubro/2012 & Análise custo-benefício. & $\begin{array}{l}\text { Conselho de ministros de Ruanda discutem o custo-benefício elaborado em } \\
\text { maio de } 2012 \text {. }\end{array}$ \\
\hline Janeiro/2013 & Visita de consultores e missão técnica. & $\begin{array}{l}\text { No preparo do seminário nacional, o Centro de Excelência enviou consultores } \\
\text { para auxiliar na organização do evento. Além do que, estes consultores } \\
\text { trabalharam de perto com o escritório do PMA de Ruanda. }\end{array}$ \\
\hline Fevereiro/2013 & Seminário Nacional. & $\begin{array}{l}\text { Seminário visa planejar e desenvolver o programa nacional de alimentação } \\
\text { escolar de Ruanda, via implementação do Plano de Alimentação Escolar. Foram } \\
\text { discutidos assuntos como: quadro legal e político, questões financeiras, } \\
\text { institucionais e de participação popular no programa de alimentação escolar. }\end{array}$ \\
\hline 2o Semestre de 2013 & Relatório de Workshop. & $\begin{array}{l}\text { Após o seminário nacional, o Centro de Excelência compilou as discussões, } \\
\text { resultados e recomendações no formato de um relatório publicado no final de } \\
2013 \text {. }\end{array}$ \\
\hline \multirow[t]{2}{*}{2014} & $\begin{array}{l}\text { Delegação de Ruanda participa de reunião } \\
\text { junto a outros países da África, América } \\
\text { Latina e Europa. }\end{array}$ & $\begin{array}{l}\text { Conhecer a metodologia de trabalho do Centro de Excelência e as políticas } \\
\text { brasileiras que inspiram a cooperação Sul-Sul em segurança alimentar. }\end{array}$ \\
\hline & $\begin{array}{l}\text { Iniciativas em compras e na alimentação } \\
\text { escolar. }\end{array}$ & $\begin{array}{l}\text { Aprovou documento que orienta a alimentação escolar no país e lançou projeto } \\
\text { piloto com base na compra local de comida. Estas iniciativas tiveram apoio } \\
\text { técnico do Centro de Excelência. }\end{array}$ \\
\hline Outubro/2014 & GCNF (Fórum Global de Nutrição Infantil) & Representantes do PMA de Ruanda participaram do evento na África do Sul. \\
\hline Novembro/2015 & $\begin{array}{l}\text { V Conferência Nacional de Segurança } \\
\text { Alimentar e Nutricional. }\end{array}$ & $\begin{array}{l}\text { Representantes da delegação de Ruanda participam da conferência que tem } \\
\text { como tema "Comida de verdade no campo e na cidade". }\end{array}$ \\
\hline
\end{tabular}

Fonte: Centro de Excelência contra a Fome; formulação própria (2018). 
Estas ações fazem parte de um apoio contínuo que o Centro de Excelência procura realizar com os países que atende. É uma forma de garantir que os programas realizados em cada país sejam programas de sucesso. Apesar de ser inegável o fato de que existem diversas dificuldades enfrentadas neste caminho, algumas delas são citadas por Daniel Silva Balaban[13]:

As dificuldades são muitas. Tanto na questão de estruturação, porque para você criar políticas, e para que essas políticas sejam bem-sucedidas, você tem que ter instituições sólidas (são aqueles que vão fazer, aqueles que vão controlar, que vão fiscalizar). Então se você não tiver instituições sólidas, você não consegue colocar em pratica essas ações. $\mathrm{O}$ problema de muitos destes países, são que eles não têm ministérios com instituições sólidas, com pessoas bem capacitadas, então tem que ter capacitação de pessoas, criação de instituições, criação de modelos, e para isso é bem complexo, denota tempo, precisa-se de recursos para que você crie estas instituições. E também outra coisa muito importante é a questão da instabilidade política.

Ruanda possui um histórico de intenções de combate à fome desde 2003, ano em que foi o primeiro país a assinar o Programa Compreensivo para o Desenvolvimento da Agricultura na África ${ }^{35}$ (CAADP - The Comprehensive Africa Agriculture Development Programme).

Com este mesmo intuito, analisando os documentos disponibilizados pelo governo de Ruanda, é possível ver que o plano estratégico formulado em $2010^{36}$ pelo Ministério da Educação de Ruanda, para ser executando entre os anos de 2010 e 2015, já possuía a pretensão de trabalhar com programas de alimentação escolar, que acontecem inclusive desde 2002 com a ajuda do próprio PMA, mas com uma formulação mais simples do que o que encontramos nos documentos formulados em $2013^{37}$, datados após o seminário de fevereiro de 2013, realizado no país para estabelecer metas e discutir o plano de ação.

Os documentos publicados pelo governo em 2013 possuem um plano mais estruturado no que se refere às diversas dimensões que a alimentação escolar pode abordar, desde a questão de pequenos agricultores e da agricultura familiar, de mecanismos de controle da

\footnotetext{
35. Mais informações sobre o Programa estão disponíveis em: htrp://fsg.afre.msu.edu/mozambique/caadp/brochurafinal_11_12_10.pdf. Consultado em 15/11/2016.

36. Documento disponivel em: http://planipolisiiep.unesco.org/upload/Rwanda/RwandaESSP20102015.pdf. Consultado em $15 / 11 / 2016$ Documentos

http://www.moh.gov.rw/fileadmin/templates/Summit3/17_Home_Grown_School_feeding.pdf disponíveis em http://www.moh.gov.rw/fileadmin/templates/summit2/National_Food_And_Nutrition_Policy_draft_29_Oct.p
} df. Consultado em 15/11/2016. saúde, até o nível federal, estadual, e escolar, entre outros pontos. Apesar de todos os esforços e do progresso já realizado, ainda são necessárias mais ações.

De acordo com um estudo chamado "O custo da fome em Ruanda"38, a não prevenção de situações de insegurança alimentar e nutricional, causam custos de quase $10 \%$ do orçamento público que o governo de Ruanda destina à saúde, além do que há uma relação direta dos gastos públicos com reprovação em escolas, e o nanismo, já que este mal acarreta baixo desempenho escolar. Isso em longo prazo gera um grande número de habitantes de baixa escolaridade, e que não possuem qualificação ao mercado de trabalho.

Este estudo conclui que a desnutrição infantil crônica presente no país não pode ser considerada um problema setorial, já que este problema repercute em diversos setores e as soluções para este problema também está em diversos setores. O desenvolvimento econômico do país deve estar ligado a um crescimento econômico inclusivo e com equidade.

Segundo um estudo realizado pelo Ministério da Agricultura de Ruanda e pelo PMA local no ano de 2016, houve nos últimos três anos uma queda no número de crianças menores de cinco anos que são diagnosticadas com desnutrição crônica, mas os números seguem sendo elevados ${ }^{39}$. De $43 \%$ das crianças que possuíam níveis de nanismo em 2012, estes números caíram para 36,7\% em $2015^{40}$.

Vale ressaltar que esse número tem sua maioria nas áreas rurais e, segundo este mesmo estudo, as principais áreas afetadas por estes números estão nas províncias do oeste de Ruanda. Visto isso, ainda seria necessário ampliar o foco de ajudas e programas de segurança social nas áreas rurais, além de diversificar as formas de renda e subsistência no campo ${ }^{41}$.

Sendo assim, Ruanda tem sido um país que demonstra nos últimos anos vontade política para ações de combate à fome e à pobreza, e tem posto em ação parte do plano de ação que foi planejado em 2012. Mas ainda é de extrema importância seguir com tais esforços, aumentando a presença nas áreas mais 
necessitadas (como é o caso das aéreas rurais), e aperfeiçoando seus programas sempre que necessário, para que números referentes à desnutrição crônica diminuam cada vez mais e de forma mais rápida.

\section{CONCLUSÕES}

Nota-se que, internacionalmente o Brasil é um país altamente reconhecido por suas experiências bemsucedidas de combate à fome e à pobreza. E foi graças a este status que, países interessados em conhecer melhor esta experiência passaram a buscar o governo brasileiro, e que pela grande demanda por compartilhar suas boas práticas, cria-se por meio de uma parceria o Centro de Excelência contra a Fome.

Com a análise feita anteriormente fica claro que se o Centro de Excelência contra a Fome não existisse, pelo menos parte dos países que foram atendidos por este organismo não teriam a oportunidade de conhecer a experiência brasileira tão a fundo e com um apoio continuado, isso por falta de recursos vindos do governo brasileiro e por falta de estrutura e de funcionários treinados, caso o governo brasileiro tivesse que gerenciar tudo sozinho. Estrutura e funcionários estes que após a criação do Centro de Excelência contra a Fome, passaram a existir pela ajuda de distintos tipos de investimentos de diferentes lugares (alguns dos financiadores são: o Departamento para o Desenvolvimento Internacional do Reino Unido, Fundação Bill \& Melinda Gates, além do financiamento por parte do próprio PMA e do governo brasileiro).

Portanto, a existência do Centro de Excelência contra a Fome foi e tem sido fator determinante para que alguns países recebam apoio e auxílio para a criação e execução de programas de combate à fome e à pobreza $^{42}$.

Sendo assim, quando não houver mais demanda por ajuda neste sentido, o Centro de Excelência haverá cumprido seu propósito.

Quando perguntado sobre a duração da existência do Centro de Excelência contra a Fome, já que esta não é uma iniciativa que tem a intenção de ser definitiva, Daniel Silva Balaban ${ }^{[13]}$ responde o seguinte:

\begin{abstract}
Acho que o momento em que o Centro cumpriu seu objetivo é quando vermos que a maioria dos países que são o foco do nosso trabalho, eles já estejam com programas nacionais funcionando e sendo desenvolvidos, e trabalhando em rede, como a pergunta passada. Vamos ver que não haverá mais a necessidade deste apoio, mas enquanto vermos que haja países batendo a nossa porta e pedindo apoio, nós temos razão de existir.
\end{abstract}

Pelo o que analisamos a experiência do Centro de Excelência contra a Fome tem sido de benefício para o PMA, por aos poucos lograr a independência de países que até então dependiam em grande parte de ajudas humanitárias; para o governo brasileiro, que internacionalmente tem conseguido exercer um papel de grande importância, ganhando, portanto, mais influência no Sistema Internacional e fortalecendo suas instituições internamente; e, é claro, aos países beneficiários da cooperação, já que recebem sem condicionalidades ajuda em assuntos internos referentes ao combate à fome e à pobreza.

A intenção desta iniciativa é criar soluções inovadoras, que se adequem da melhor forma a cada país, e não uma lógica de transferência de política que não leva em conta as diferenças de cada sistema político. Sempre que possível também, trabalhando em redes para que a cooperação e o trabalho conjunto sejam fatores que desencadeiem a solidariedade entre estas nações, que enfrentam problemas muitas vezes similares.

É preciso continuar incentivando que práticas bem-sucedidas de combate à fome continuem sendo disseminadas cada vez mais, e que pressões internacionais sejam feitas aos países que ainda não possuem iniciativas do tipo, para que a falta de vontade política deixe de ser um impedimento para que a fome acabe em alguns lugares.

\section{REFERÊNCIAS}

[1] Bender K, Keller S, Willing H. The Role of International Policy Transfer and Diffusion for Policy Change in Social Protection - A Review of the State of the Art [internet]. 2014. [acesso em 15 nov 2016]. IZNE Social Protection Working Paper 14/1. International Policy Learning and Policy Change: Scientific Inputs for the Dialogue on Social Protection with Global Partners; 2014. Disponível em: https://www.hbrs.de/files/izne/policy_diffusion_1.pdf.

42 Mais informaçõos sobre a importância desta difusão de experiências disponiveis em: https://nacoesunidas.org/cooperacac-

com-brasil-e-crucial-para-ampliar-protecao-social-na-africa-tevela-pesquisa-da-onu. Consultado em 30/04/2018. 
[2] Global Humanitarian Assistance - GHA. Report 2015. A development initiative [internet]. Bristol: GHA; 2015 [acesso em 29 abr 2018]. Disponível em: http://devinit.org/wpcontent/uploads/2015/10/GHA2015P_Friendly2.pdf

[3] Drake LJ. Global School Feeding Sourcebook: lessons from 14 countries. New Jersey: Imperial College Press [internet]. 2016. [acesso em 09 nov 2016]. Disponível em: https://openknowledge.worldbank.org

[4] Dolowitz DP, Marsh D. Learning from abroad: the role of policy transfer in contemporary policy-making. Governance: an international journal of policy and administration. 2000;13(1):524.

[5] Dolowitz DP, Marsh D. The Future of Policy Transfer Research. Political Studies Review. 2012;10:339-345.

[6] Benson D, Jordan A. What Have We Learned from Policy Transfer Research? Dolowitz and Marsh Revisited. Political Studies Review. 2011;9:366-378.

[7] Dolowitz DP, Marsh D. Who learns what from whom: a review of the policy transfer literature. Political Studies - Oxford. 1996;44:343-357.

[8] World Food Programme - WFP. Centro de Excelência contra a Fome. Relatório Anual 2014 [internet]. 2014. [acesso em 03 dez 2014]. Disponível em: http://www.wfp.org

[9] Peixinho AML. Um resgate histórico do Programa Nacional de Alimentação Escolar - PNAE [dissertação]. [internet]. São Paulo: Universidade Federal de São Paulo; 2011. [acesso em 15 nov 2016]. Disponível em: http://www2.unifesp.br

[10] Chitolina L, Foguel MN, Menezes-Filho N. O impacto da expansão do Programa Bolsa Família sobre a frequência escolar. Centro Internacional de Políticas para o Crescimento Inclusivo - № 234 [internet]. 2013 [acesso em 15 nov 2016]. Disponível em: http://www.ipc-undp.org/pub/port/IPCOnePager234.pdf

[11] Chmielewska D, Souza D. The food security policy context in Brazil. Centro Internacional de Políticas para o Crescimento Inclusivo. Country Study - № 22 [internet]. 2011 [acesso em 15 nov 2016]. Disponível em: http://www.ipcundp.org/pub/IPCCountryStudy22.pdf

[12] International Policy Centre for Inclusive Growth. Structured Demand and Smallholder Farmers in Brazil: the Case of PAA and PNAE. Brasília, United Nations Development Programme (UNDP). [internet]. 2013. [acesso em 15 nov 2016]. Disponível em: http://www.ipc-undp.org/pub/IPCTechnicalPaper7.pdf

[13] Balaban DS. Entrevista concedida à Nicole Figueiredo pelo Diretor do Centro de Excelência contra a Fome do Programa Mundial de Alimentos, na sede do Centro de Excelência contra a Fome do Programa Mundial de Alimentos, em Brasília. In: Figueiredo N. A Cooperação Sul-Sul brasileira em segurança alimentar e o trabalho do Centro de Excelência contra a Fome do Programa Mundial de Alimentos. São Paulo: Universidade Federal de São Paulo (UNIFESP); 2017.

[14] Silva JG, Takagi M. In: Rocha M. Segurança Alimentar: um desafio para acabar com a fome no Brasil. São Paulo: Editora Fundação Perseu Abramo; 2004 (Coleção Cadernos da Fundação Perseu Abramo).

[15] Brasil. Lei no 11.346, de 15 de setembro de 2006. Cria o Sistema Nacional de Segurança Alimentar e Nutricional - SISAN com vistas em assegurar o direito humano à alimentação adequada e dá outras providências. Brasília: Diário Oficial da União. 15 set 2006.

[16] Brasil. Conselho Nacional de Segurança Alimentar e Nutricional (CONSEA). Construção do Sistema e da Política Nacional de Segurança Alimentar e Nutricional: a experiência brasileira [internet]. 2009. [acesso em 12 mai 2016]. Disponível em: http://www4.planalto.gov.br/consea/publicacoes

[17] Ramanzini Júnior H, Mariano MP, Almeida RAR. As Diferentes Dimensões da Cooperação Sul-Sul na Política Externa Brasileira. In: Ramanzini Júnior H, Ayerbe LF. Política Externa Brasileira: Cooperação Sul-Sul e Negociações Internacionais. São Paulo: Cultura Acadêmica, 2015. p. 13-49.

[18] Buani CA. Da reconstrução de Estado ao desenvolvimento: por uma nova legitimidade das Nações Unidas - o caso do Programa Mundial de Alimentos em Ruanda. Brasília(DF): UniCEUB; 2014.

[19] Oliveira LDSW, Eluiza AMLF, Sproesser DO, Luiz R. Avaliação de Políticas Públicas de Segurança Alimentar em Países com Diferentes Níveis de Desenvolvimento. Agroalim. 2010;16(31):15-29.

[20] World Food Programme (WFP). Centro de Excelência contra a Fome. Relatório Anual 2015 [internet]. 2016. [acesso em 10 mai 2016]. Disponível em: http://documents.wfp.org

[21] World Food Programme (WFP). Centro de Excelência contra a Fome. Relatório Anual 2012 [internet]. 2013. [acesso em 02 dez 2014]. Disponível em: http://www.wfp.org

[22] World Food Programme (WFP). Centro de Excelência contra a Fome. Relatório Anual 2013 [internet]. 2014. [acesso em 02 dez 2014]. Disponível em: http://www.wfp.org

[23] World Food Programme (WFP). P4P - Purchase for Progress: The Story, Connecting farmers to markets [internet]. 2015. [acesso em 16 nov 2016]. Disponível em: http://www.wfp.org

[24] Prado CM. Entrevista concedida à Nicole Figueiredo pela Gerente de Cooperação Sul-Sul Trilateral com Organismos Internacionais da Agência Brasileira de Cooperação, na sede da Agência Brasileira de Cooperação, em Brasília. In: Figueiredo N. A Cooperação Sul-Sul brasileira em segurança alimentar e o trabalho do Centro de Excelência contra a Fome do Programa 
Mundial de Alimentos. São Paulo: Universidade Federal de São Paulo (UNIFESP); 2017.

[25] World Food Programme (WFP). Rwanda: National Consultations on Home Grown School Feeding. Kigali [internet]. 2013 [acesso em 13 nov 2016]. Disponível em: https://brazilcentreofexcellence.files.wordpress.com 